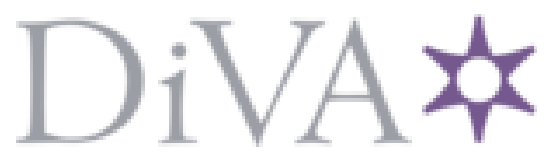

http://www.diva-portal.org

\title{
Postprint
}

This is the accepted version of a paper published in Journal of the American Chemical Society. This paper has been peer-reviewed but does not include the final publisher proofcorrections or journal pagination.

Citation for the original published paper (version of record):

Margarita, C., Andersson, P G. (2017)

Evolution and Prospects of the Asymmetric Hydrogenation of Unfunctionalized Olefins

Journal of the American Chemical Society, 139(4): 1346-1356

https://doi.org/10.1021/jacs.6b1069o

Access to the published version may require subscription.

N.B. When citing this work, cite the original published paper.

Permanent link to this version:

http://urn.kb.se/resolve?urn=urn:nbn:se:su:diva-141378 


\title{
$\mathrm{J}$

\section{Evolution and Prospects of the Asymmetric Hydrogenation of 2Unfunctionalized Olefins}

\author{
3 Cristiana Margarita and Pher G. Andersson*(i) \\ 4 Department of Organic Chemistry, Stockholm University, S-10691 Stockholm, Sweden
}

\begin{abstract}
The catalytic enantioselective hydrogenation of prochiral olefins is a key reaction in asymmetric synthesis. Its relevance applies to both industry and academia as an inherently direct and sustainable strategy to induce chirality. Here we briefly recount the early breakthroughs concerning the asymmetric hydrogenation of largely unfunctionalized olefins, from the first reports to the advent of chiral Crabtree-like catalysts. The mechanism and its implications on the enantioselectivity are shortly discussed. The main focus of this Perspective lies on the more recent advances in the field, such as the latest developed classes of ligands and the opportunity to employ more Earth-abundant metals. Therefore, separate sections consider iridium N,P-, NHC-, P,S-, and -O,Pcatalysts, and rhodium, palladium, cobalt, and iron catalysts. Finally, the remaining unsolved challenges are examined, and the potential directions of forthcoming research are outlined.
\end{abstract}

\section{$23 \square$ INTRODUCTION}

24 The enantioselective hydrogenation of olefins is currently 25 recognized as one of the most fundamental transformations in 26 asymmetric catalysis and represents an expedient strategy for 27 the creation of stereogenic centers in target molecules. The 28 process can rely on advantageous features such as excellent 29 atom economy, quantitative yields, and high levels of 30 enantioselectivity for a wide range of alkene substrates. ${ }^{1}$ All 31 these factors contribute to the method's attractiveness for both 32 industrial applications and academic research. The field has 33 seen an impressive degree of development since the early 34 reports of successful asymmetric hydrogenation mediated by $35 \mathrm{Rh}(\mathrm{I})$ - and $\mathrm{Ru}(\mathrm{II})$-diphosphine chiral catalysts, ${ }^{2}$ a discovery 36 leading up to the 2001 Nobel Prize awards to Noyori ${ }^{3}$ and 37 Knowles, $^{2 \mathrm{i}}$ and it has continued to draw the interest of 38 numerous research groups to date. The $\mathrm{Rh}(\mathrm{I})$ and $\mathrm{Ru}(\mathrm{II})$ 39 catalytic systems have since been applied extensively to 40 diversely functionalized olefins. They still constitute the optimal 41 choice for the synthesis of optically active $\alpha$-amino acids and 42 many pharmaceutically relevant compounds. However, they 43 have mainly exhibited high efficiency and stereocontrol on 44 substrates possessing a coordinating group in proximity of the 45 $\mathrm{C}=\mathrm{C}$ bond. With only a few exceptions, ${ }^{4}$ they resulted 46 prevalently in low activity and enantioselectivity when tested on 47 minimally functionalized olefins, which can be defined as those 48 not containing any coordinating functional group directly 49 connected to the double bond. ${ }^{5}$ In order to overcome these 50 limitations and open the field of asymmetric hydrogenation to 51 more general classes of olefins, different catalytic systems have been developed and evaluated for alkenes lacking metal- 52 chelating functional groups. Among other purposes, the interest 53 in the enantioselective reduction of minimally decorated double 54 bonds is related to the possibility of stereocontrol on remote 55 alkyl regions in the synthesis of natural and biologically active 56 compounds.

The first promising reports of chiral catalysts able to 58 selectively handle unfunctionalized olefins involved metal- 59 locenes ${ }^{6}$ and organolanthanide ${ }^{7}$ complexes. They could hydro- 60 genate 2-phenyl-1-butene up to $96 \%$ enantiomeric excess (ee) 61 but required very low temperatures, a base for catalyst 62 activation, and complicated ligand preparation, which greatly 63 inhibited their further development. Nevertheless, outstanding 64 examples of metallocene catalysts were described by Buchwald, 65 who first reported on the use of a titanocene catalyst ${ }^{6 \mathrm{~h}}$ for the 66 hydrogenation of trisubstituted nonfunctionalized olefins in up 67 to $99 \%$ ee, and later developed a zirconocene catalyst ${ }^{6 m}$ for the 68 hydrogenation of the even more challenging class of 69 tetrasubstituted olefins with ee's exceeding 90\%. 70

The central role that iridium currently plays in homogeneous 71 catalytic hydrogenation can be traced back to the development 72 of Crabtree's catalyst $1,\left[\operatorname{Ir}(\operatorname{cod})\left(\mathrm{PCy}_{3}\right)(\mathrm{py})\right]^{+} \mathrm{PF}_{6}^{-}$(Figure 1, $73 \mathrm{fl}$

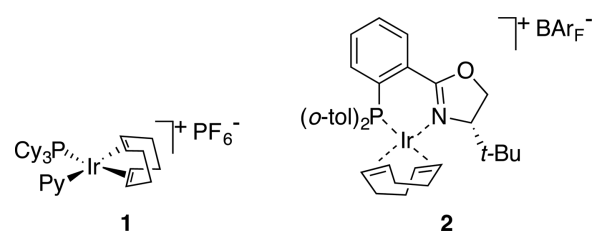

Figure 1. Crabtree's catalyst and Pfaltz's Ir-PHOX catalyst.

cod $=1,5$-cyclooctadiene) ${ }^{8}$ an achiral cationic complex which 74 demonstrated exceptionally high activity toward olefins lacking 75 neighboring coordinating groups, surprisingly including also 76 tetrasubstituted olefins. The catalyst, employed as a crystalline 77 salt, showed good stability against oxidation, making it easier to 78 handle than most air-sensitive organometallic compounds, 79 despite its impressive reactivity. Crabtree's work opened the 80 possibility for further development of this kind of system in an 81 asymmetric version.

\section{EARLY DEVELOPMENTS}

In 1993, the groups of Helmchen, ${ }^{9}$ Williams, ${ }^{10}$ and Pfaltz $^{11} 84$ introduced the use of chiral phosphinooxazoline N,P-ligands 85 (PHOX) in asymmetric catalysis. In 1997, Pfaltz used PHOX 86 ligands to generate the first series of chiral counterparts of 87

Received: October 12, 2016

Published: January 7, 2017 
88 Crabtree's catalyst (2, Figure 1) and successfully applied it to 89 the asymmetric hydrogenation of imines. ${ }^{12}$ Eventually, the 90 catalysts were also employed in a number of aryl-substituted 91 prochiral olefins, resulting in excellent enantioselectivity (98\% 92 ee for (E)- $\alpha$-methylstilbene). ${ }^{13}$ At the same time, some 93 important issues related to the catalyst stability were solved. 94 It had already been observed by Crabtree that the Ir cationic 95 catalyst suffered from deactivation due to the formation of 96 hydride-bridged trimers. This problem was solved by Pfaltz, 97 replacing the counteranion $\mathrm{PF}_{6}^{-}$with the more weakly 98 coordinating species tetrakis[3,5-bis(trifluoromethyl)phenyl]99 borate $\left(\mathrm{BAr}_{\mathrm{F}}^{-}\right)$. This variation granted a dramatic increase in 100 the reaction rate, ${ }^{14}$ and it also allowed lowering the catalyst 101 loadings to less than $1 \mathrm{~mol} \%$.

102 These findings prompted enormous attention to the design 103 of chiral Ir complexes with the purpose of expanding the 104 substrate scope to include a broader variety of olefins, resulting 105 in the preparation and screening of a large variety of Ir-N,P106 ligated catalysts. It still constitutes a prioritized research goal for 107 the enantioselective hydrogenation of unfunctionalized alkenes. 108 The Pfaltz group continued to study and develop new 109 versions of the PHOX complexes, modifying the ligand 110 backbone, and built a library of very efficient catalysts for a 111 variety of minimally functionalized olefins. ${ }^{15}$ Successive work 112 included pyridine and quinoline rings in ligands' structures and 113 allowed the remarkable asymmetric hydrogenation of purely 114 alkyl-substituted substrates in high ee. ${ }^{16}$ An excellent 115 application of these systems to total synthesis provided $\gamma$ 116 tocopherol as a single diastereoisomer in $98 \%$ ee, controlling 117 two stereocenters in one reductive step. ${ }^{16 \mathrm{~b}}$ The various 118 developed ligands also enabled the asymmetric hydrogenation 119 of different classes of substrates, including allylic alcohols, $\alpha, \beta$ 120 unsaturated esters, ${ }^{17}$ furan derivatives, ${ }^{18}$ boronic esters, ${ }^{19}$ and 121 tetrasubstituted olefins. ${ }^{20}$

122 Another class of notably effective catalysts involve C,N123 ligands such as 3 (Figure 2), developed by Burgess. ${ }^{21}$ They

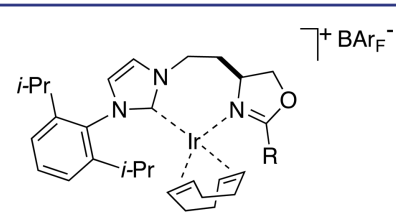

3

Figure 2. An example of Burgess's N-heterocyclic carbene catalysts.

124 contain an N-heterocyclic carbene (NHC) as coordination site 125 in place of phosphines and provide high enantioselectivities for 126 a range of trisubstituted minimally functionalized olefins and 127 vinyl ethers. ${ }^{22}$

128 Various classes of chiral N,P-ligands have been developed by 129 the Andersson group. The investigation of different bicyclic 130 heteroaromatic rings led to highly enantioselective hydro131 genations by means of oxazole--, ${ }^{23}$ thiazole- ${ }^{24}$ and imidazole132 based $^{25}$ iridium catalysts 4, 5, and 6 (Figure 3). Other 133 successful ligands were constructed around a 2-aza-norbornane 134 chiral backbone (7, Figure 3). ${ }^{26}$ The diverse nature of the 135 different heterocycles also enables tuning the electron density 136 on the $\mathrm{N}$-donor atom, which in turn affects the electrophilicity 137 of the iridium center. These iridium catalysts perform 138 excellently on the typically tested trisubstituted nonfunctional139 ized olefins and also allow extending the substrate scope to
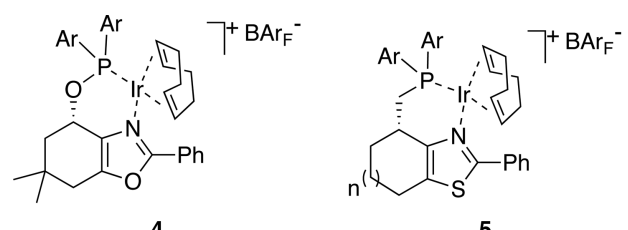

5

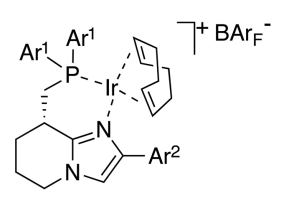

6

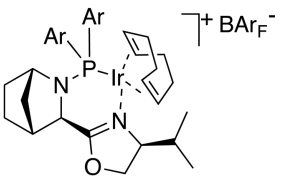

7

Figure 3. Catalysts developed by the Andersson group.

vinyl silanes, ${ }^{27}$ fluorinated olefins, ${ }^{25,28}$ vinyl boronates ${ }^{29}$ and 140 enol phosphinates. ${ }^{30}$

Several comprehensive reviews ${ }^{5,31}$ have covered these major 142 advances in the asymmetric hydrogenation of nonfunctional- 143 ized olefins; hence, this Perspective is mainly focused on the 144 recent reports in the field (up to 2016) and the potential future 145 directions of research.

146

To evaluate the efficiency and selectivity of the catalytic 147 systems in asymmetric hydrogenation, unfunctionalized trisub- 148 stituted olefins have generally been employed as benchmark 149 substrates, especially 1,2-diarylalkenes. In some cases disub- 150 stituted terminal olefins are also included in the screening, but 151 reaching high enantioselectivity for these compounds has 152 normally shown to be more problematic and might require 153 more substrate-specific catalysts. Finally, exclusively alkyl- 154 substituted and tetrasubstituted alkenes represent even more 155 challenging substrates, appearing only in a limited number of 156 reports. $6 \mathrm{~m}, 20,32$

157

\section{MECHANISM AND SELECTIVITY}

158

The advent of iridium Crabtree-type chiral catalysts started the 159 evolution of the hydrogenation of hindered alkenes without 160 coordinating functional groups. The mechanistic aspects of the 161 Ir-catalyzed hydrogenation and the origin of stereoselectivity 162 have been studied and discussed by various contributors. ${ }^{33}$ This 163 section will shortly describe the proposed catalytic cycle most 164 widely accepted today.

165

In 2003, Brandt and co-workers carried out density 166 functional theory studies employing a truncated model for an 167 Ir-N,P-catalyst and proposed the mechanism to involve an 168 $\operatorname{Ir}(\mathrm{III}) / \mathrm{Ir}(\mathrm{V})$ catalytic cycle. $^{34}$ In that study, starting from 169 complexes $\left[\mathrm{Ir}-(\mathrm{H})_{2}(\mathrm{~N}, \mathrm{P}) \text { (alkene)S }\right]^{+}$(alkene = ethane, $\mathrm{S}=170$ solvent), the coordinated solvent molecule was replaced by a 171 $\mathrm{H}_{2}$ molecule, forming intermediate A (Figure 4). The migratory $172 \mathrm{f} 4$ insertion step, which was identified as rate-determining due to 173 the significant calculated energy barrier, occurred simulta- 174 neously and was also facilitated by the oxidative addition of the 175 coordinated dihydrogen molecule to form the $\operatorname{Ir}(\mathrm{V})$ species B. 176 Reductive elimination, liberating the alkane product, and 177 coordination of new dihydrogen and alkene molecules 178 regenerated species A. Kinetic studies have shown that the 179 reaction is first-order in hydrogen pressure, but this could be 180 related to $\mathrm{H}_{2}$ diffusion in the solution, which can become rate- 181 limiting when alkene hydrogenation is fast. It has been shown 182 for $\operatorname{Ir}(\mathrm{PHOX})$ catalysts that the reaction is diffusion-limited at 183 room temperature. ${ }^{14,15 b, 35}$ Successive extended calculations on 184 the full structure of a reported Ir-N,P-catalyst further reinforced 185 


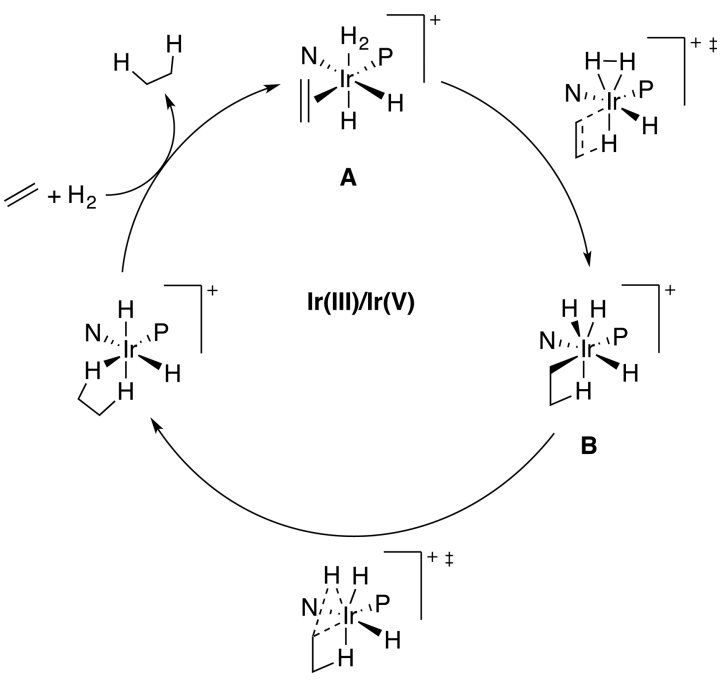

Figure 4. Proposed $\operatorname{Ir}(\mathrm{III}) / \operatorname{Ir}(\mathrm{V})$ catalytic cycle.

186 the proposed $\operatorname{Ir}(\mathrm{III}) / \operatorname{Ir}(\mathrm{V})$ mechanism as the lowest energy 187 path for the reaction, investigating both gas-phase and solvent 188 field conditions. ${ }^{36}$

189 This reaction pathway has been also supported by other 190 recent computational investigations ${ }^{37}$ and experimental find191 ings. NMR studies by Pfaltz ${ }^{38}$ led to the identification of a 192 fundamental intermediate, an $\operatorname{Ir}(\mathrm{III})$ dihydride alkene complex. 193 This species was defined as a resting state of the catalyst, and it 194 demonstrated the requirement of the coordination of an 195 additional dihydrogen molecule prior to the migratory insertion 196 step.

197 The catalytic cycle shown in Figure 4 is proposed to be 198 operating for most unfunctionalized olefins, with few 199 exceptions.

200 In order to rationalize the stereoselectivity of the hydro201 genation, the steric environment around the incoming olefin, 202 which is coordinated trans to phosphorus, must be taken into 203 account. The possibility for the olefin to coordinate is 204 determined by the orientation of the $\mathrm{R}$ group near the nitrogen 205 of the N,P-ligand (commonly an aryl or a bulky alkyl), which 206 points to the alkene coordination site. The position of this 207 steric bulk in the chiral N,P-ligands can be visualized by means 208 of a quadrant selectivity model, indicating which areas will be 209 more hindered, depicted from the perspective of the incoming 210 olefin (Figure 5a). Gray quadrants represent the most occupied 211 areas, which dictate the preferential coordination of one face of 212 the alkene in order to minimize sterical interactions, with the $\mathrm{R}$ 213 group occupying the lower left quadrant (i) or the upper one 214 (ii), depending on the ligand structure and absolute 215 configuration.

216 This quadrant model can be used to predict the stereo217 chemical outcome of the majority of the N,P-Ir-catalyzed 218 hydrogenations of prochiral olefins. It has proven reliable for a 219 wide range of substrates, ${ }^{36}$ where the stereoselection is mainly 220 directed by steric hindrance rather than dominated by 221 electronic effects or coordinating groups. Since the preferential 222 coordination depends on the position of the smallest 223 substituent $(\mathrm{H})$ on the substrate, olefins are not discriminated 224 based on the prochiral carbon atom, and this results in the 225 formation of opposite enantiomers upon hydrogenation of an $226(E)$ - or $(Z)$-olefin. This is shown in Figure $5 \mathrm{~b}$ for the case of a 227 catalyst having the lower left quadrant (i) as the most occupied.

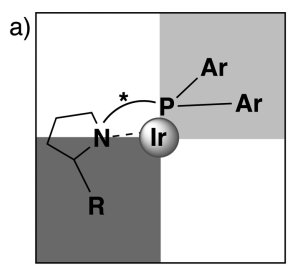

i
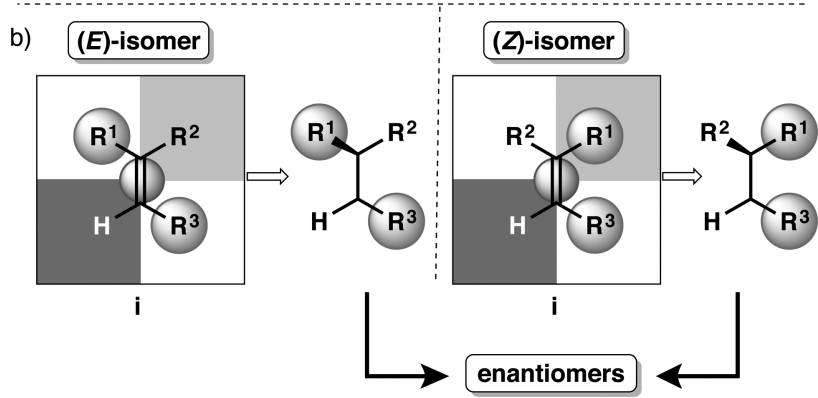

Figure 5. (a) Quadrant selectivity model. (b) Hydrogenation of isomeric alkenes.

\section{LATEST RESULTS}

It might seem that most issues have been largely overcome 229 during decades of research on the asymmetric hydrogenation of 230 olefins. This is certainly true in the sense that the large number 231 of very efficient catalysts now available make it possible to 232 achieve high enantioselectivities for a wide range of olefin 233 classes, generally operating under mild conditions and at low 234 catalyst loadings. Optimization efforts have predominantly 235 revolved around the now well-established, wide variety of Ir- 236 based catalysts, which continue to provide optimal results in the 237 hydrogenation of various classes of substrates. However, some 238 unsolved limitations in the applicability of these catalytic 239 systems can still be found and will be analyzed herein after a 240 discussion of recently published results. The selected reports 241 regard exclusively catalytic systems that were applied to largely 242 unfunctionalized olefins. Results on some unusual non- 243 coordinating groups such as boronates are also covered. A 244 very interesting part of the most recent advances involves the 245 use of cheaper bulk metals as alternatives to iridium; therefore, 246 successful examples of cobalt and iron catalysis are presented 247 and arranged in separate sections.

The vast majority of reported research in asymmetric 249 hydrogenation still concerns the use of Crabtree-type catalysts. 250 Considerable advancements in the design of chiral ligands for 251 iridium complexes have generated many innovative classes of 252 catalysts, exploring diverse possibilities of tuning sterics and 253 donor properties. For this reason, the large number of reports 254 in iridium catalysis are grouped according to the donor atoms 255 in the ligand coordination sites.

256

Iridium N,P-Catalysts. Recent advances in the develop- 257 ment of ligands for Ir catalysis have been made by several 258 research groups. For example, the group of Pàmies and Diéguez 259 has lately been very active in the preparation of sugar-based 260 ligands. ${ }^{39}$ In particular, pyranoside phosphite-oxazoline struc- 261 tures 8 (Figure 6) were investigated, evaluating rigid biarylic $262 \mathrm{f} 6$ moieties on the phosphorus to modularly generate a ligand 263 library.

264

This approach afforded chiral iridium catalysts with improved 265 substrate versatility, which achieved excellent ee's (up to 99\%) 266 for a broad range of unfunctionalized model alkenes: diaryl, 267 

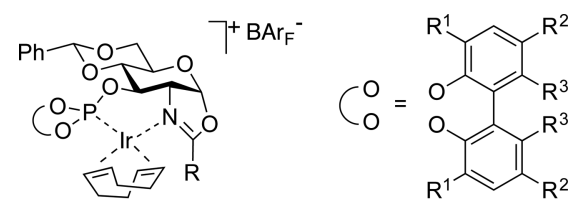

8

Figure 6. Pyranoside-based catalysts.

268 dialkyl, and cyclic trisubstituted, triaryl-substituted, and also 269 1,1-disubstituted terminal olefins. Similarly, good results (>90\% 270 ee) were obtained for some of these substrates when using a 271 simpler version of the ligands, having an ortho-tolyl phosphinite 272 function. $^{40}$ The group also explored the possibility to carry out 273 the hydrogenation of some olefins in propylene carbonate (PC) 274 as an alternative, environmentally friendly solvent, still 275 maintaining the excellent enantioselectivities. Another contri276 bution by Pàmies and Diéguez showed that modification of 277 previously developed phosphite-oxazoline catalysts to thiazo-

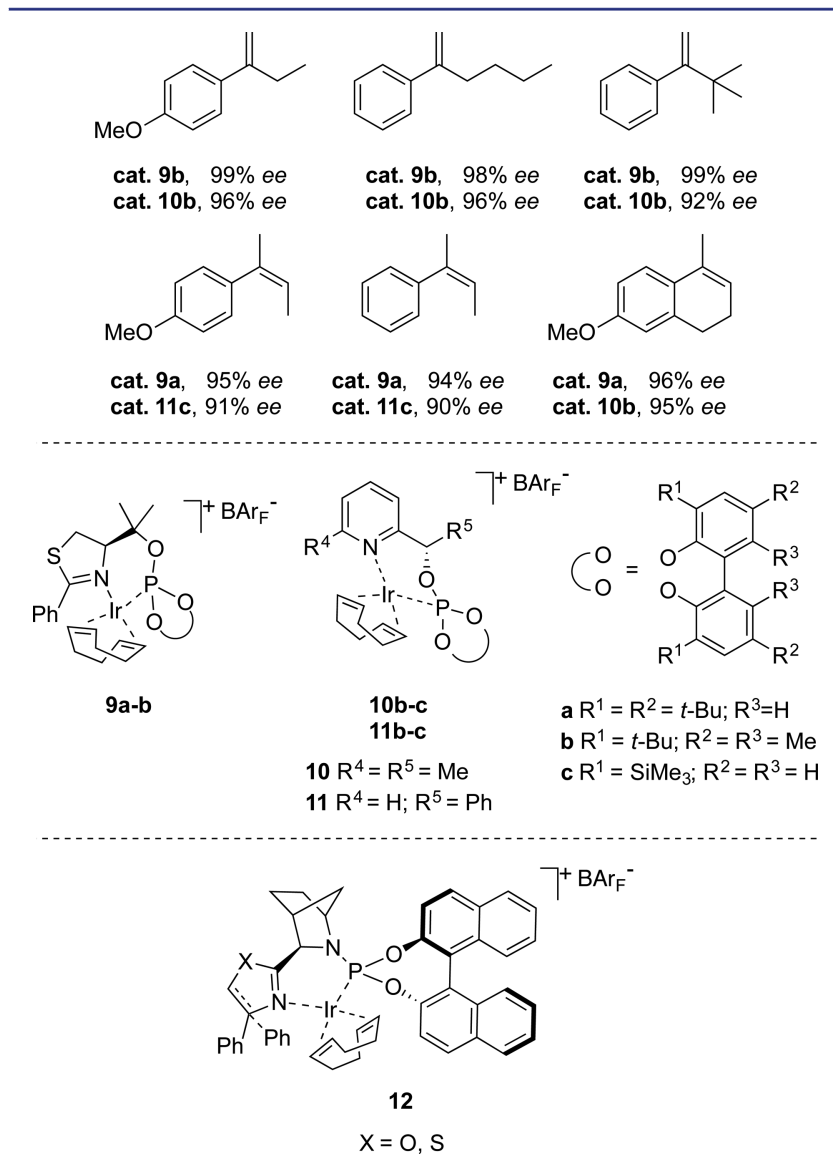

Figure 7. Selected results for biaryl-phosphite pyridine, phosphitethiazoline, and phosphoramidite-based catalysts.

279 substrate scope. $^{41}$ The hydrogenation of $(E)$ - and $(Z)$ 280 trisubstituted olefins resulted in high enantioselectivities as 281 expected, but it was moreover possible to achieve exceptional 282 ee's, in the range of $90-99 \%$, for 1,1-disubstituted terminal 283 olefins. Later studies implemented biaryl phosphites on 284 pyridine-containing ligands, without the use of sugar frag285 ments. $^{42}$ This generated iridium catalysts 10 and $\mathbf{1 1}$ (Figure 7), 286 whose structures resemble more closely Pfaltz's pyridine-based 287 ligands $^{16-19}$ and were found to give high stereoselectivity toward both $(E)$ - and $(Z)$-trisubstituted olefins, as well as more 288 demanding dihydronaphthalenes and triaryl-substituted sub- 289 strates (95-98\% ee). Excellent results (90-99\% ee) could also 290 be achieved on several vinyl boronates and terminal olefins 291 (>90\% ee).

292

An interesting example of ligand design was reported when 293 the Diéguez and Andersson groups collaborated to prepare and 294 evaluate a library of catalysts containing the 2-aza-norbornane 295 framework, an oxazoline or thiazole ring, and a biaryl phosphite 296 moiety. ${ }^{43}$ The resulting phosphoramidite-based ligands 12297 (Figure 7) showed good versatility and resulted in hydro- 298 genated products in higher ee's than the first generation of this 299 type of ligands. Demanding terminal olefins were also well 300 tolerated, and improved enantioselectivities were reached for a 301 number of these compounds; however, some of the aryl-alkyl- 302 substituted ones were still hydrogenated in moderate ee's due 303 to competitive isomerization to the $(E)$-isomers.

A direct and powerful strategy to access chiral cyclohexanes 305 by asymmetric hydrogenation of diversely functionalized 1,4- 306 cyclohexadienes has been studied and optimized by the 307 Andersson group. ${ }^{44}$ Among the hydrogenation substrates, 308 many examples of purely alkyl-substituted dienes can be 309 found, for which thiazole- or imidazole-based iridium catalysts 310 produced excellent enantioselectivities (up to 99\%). The 311 predominant formation of the trans isomer was observed for 312 1,3-substituted carbocycles. Successively, the scope of this 313 methodology has been further improved by fine variation of 314 aryl substituents on the imidazole-type ligands (6, Figure 8), $315 \mathrm{f} 8$ which afforded even more efficient, versatile, and enantio- 316 selective catalysts. ${ }^{45}$

An important feature to consider in this work lies in the 318 possibility to preserve some of the double bonds on the cyclic 319 structures, leaving room for further synthetic manipulations. 320 This has proven to be consistently attainable in the case of 321
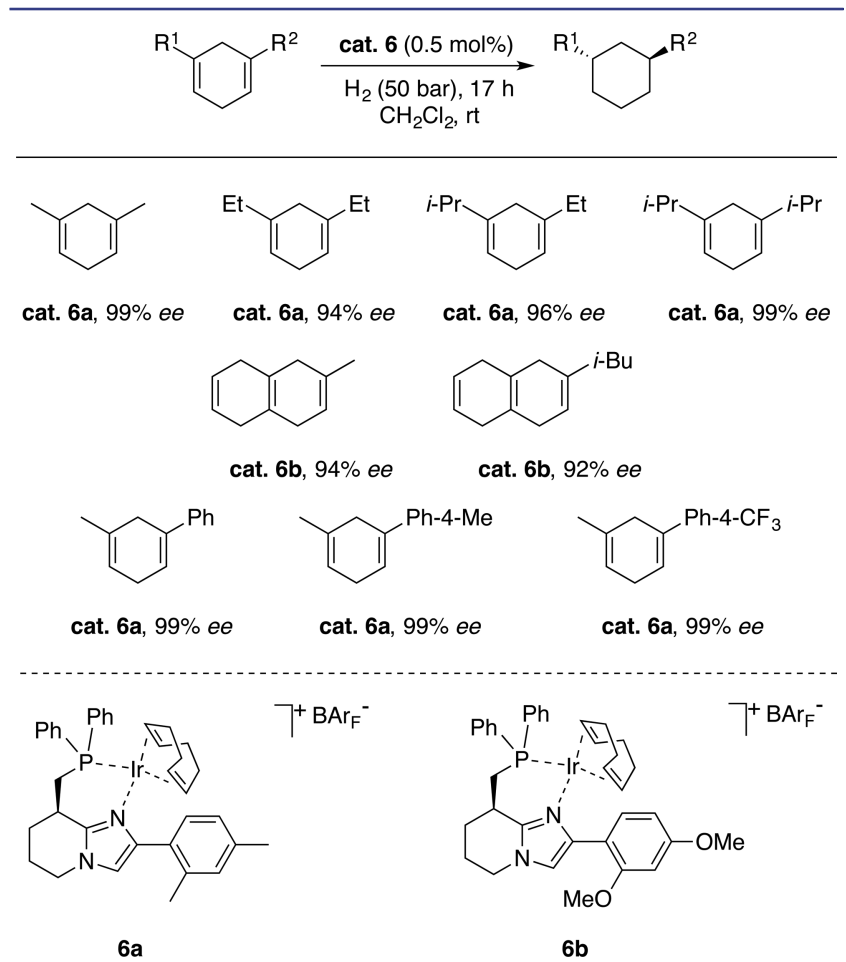

Figure 8. New generation of imidazole-based catalysts for the asymmetric hydrogenation of cyclohexadienes (selected results). 
322 tetrasubstituted olefins. In addition, it was also found possible 323 to discriminate between two differently trisubstituted olefins on 324 some aryl-containing cyclohexadienes, and they could be 325 converted to either monohydrogenated products or fully 326 saturated chiral cyclohexanes, depending on hydrogen pressure 327 and reaction time; in both cases, $99 \%$ ee was maintained 328 (Figure 9).

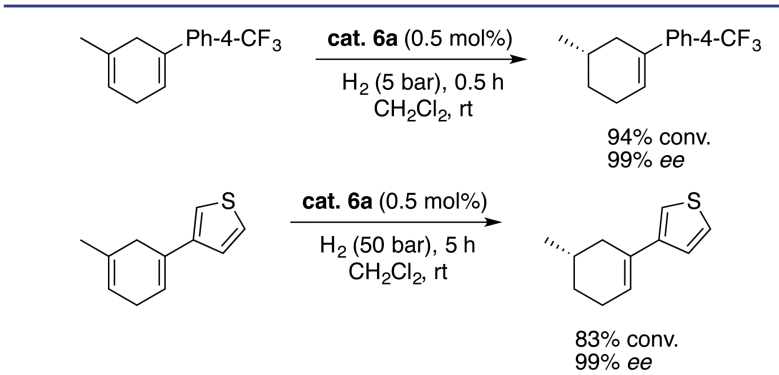

Figure 9. Regioselective hydrogenation of cyclohexadienes.

329 In 2014, the synthesis of new pyridine-based N,P-ligands 330 with a five-membered fused carbocycle (13, Figure 10) was

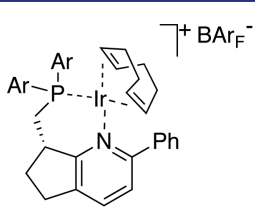

13 $\mathrm{Ar}=\mathrm{Ph}, \mathrm{o}-\mathrm{Tol}$

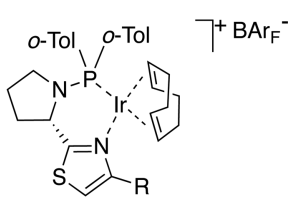

14
Figure 10. Examples of new pyridine- and proline-based catalysts.

331 described by Andersson and co-workers. ${ }^{46}$ This group of 332 catalysts differs from previous generations employing pyridine 333 as a $\mathrm{N}$-donor since they contain a carbon atom instead of 334 oxygen as a linker between the ligand chiral backbone and the 335 phosphorus. Earlier ligands with a $\mathrm{P}-\mathrm{O}$ bond are generally less 336 stable. ${ }^{16 a}$ The results obtained in the asymmetric hydrogenation 337 of some typically tested trisubstituted olefins proved the 338 catalysts' efficiency, reaching full conversion and ee's in the 339 range of other heterocyclic ligands ( $>90 \%$ ee). Thiazole340 substituted ligands 14 (Figure 10) derived from proline also 341 showed high activity and good enantioselectivities when used in 342 the Ir-catalyzed hydrogenation of certain trisubstituted and 343 endocyclic nonfunctionalized alkenes (84-97\% ee). ${ }^{47}$

f11 344 Using the BIPI ligands class (15, Figure 11), which had 345 already performed successfully in the Rh-catalyzed asymmetric 346 hydrogenation of various functionalized olefins, a set of novel 347 iridium catalysts was developed by Busacca, $\mathrm{Qu}$, and 348 Senanayake. ${ }^{48}$ In order to apply this system to unfunctionalized 349 olefins, a ligand optimization study was carried out, varying the 350 substituents at the phosphorus and on the imidazoline ring. 351 Having cyclohexyl groups on both functions and a fluorine 352 atom on the naphthyl peri-position provided a very efficient 353 catalyst for hydrogenating challenging tetrasubstituted olefins, 354 yielding an excellent $96 \%$ ee for the model substrate 2,3355 dimethylindene using 1 bar of $\mathrm{H}_{2}$ ( 2 mol\% of catalyst). A $90 \%$ 356 ee was obtained for dimethyl dihydronaphthalene, and high 357 selectivity was also achieved for two representative trisub358 stituted olefins. Pyridyl-dihydrobenzooxaphosphole (BoQ359 Phos) ligands 16 (Figure 11) were also evaluated in the Ir360 catalyzed hydrogenations of unfunctionalized olefins. ${ }^{49}$

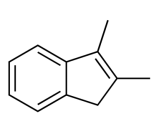

cat. $1596 \%$ ee

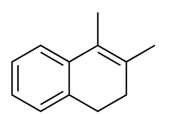

cat. 15 90\% ee

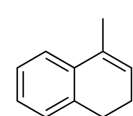

cat. $1698 \%$ ee cat. $1780 \%$ ee

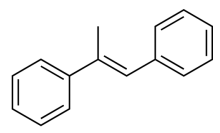

cat. $1790 \%$ ee
15

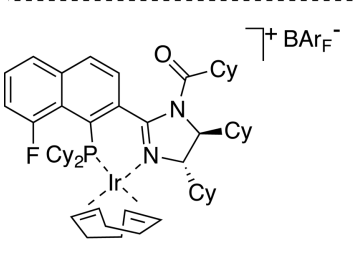

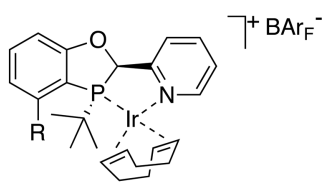

16

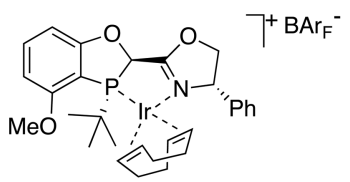

17

Figure 11. BIPI, BoQPhos, and LalithPhos catalysts.

Although high conversions and good enantioselectivities (76- 361 $90 \%$ ee) were obtained for different substrates (Figure 11), the 362 BIPI-derived catalysts $\mathbf{1 5}$ provided better results. The hydro- 363 genation of prochiral unfunctionalized dihydronaphthalenes 364 was improved with the design of new phosphine-oxazoline 365 ligands 17 (LalithPhos, Figure 11), and various 1-aryltetralins 366 were thus obtained in ee's higher than $90 \%$ using 1 atm of $\mathrm{H}_{2}{ }^{50}{ }_{367}$

The group of Van der Eycken has investigated chiral 368 ferrocene-derived N,P-ligands 18 (Figure 12), whose iridium $369 \mathrm{f} 12$

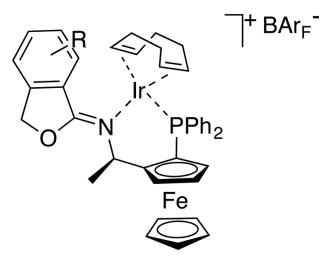

18

Figure 12. Ferrocene N,P-catalysts.

complexes were tested in the hydrogenation of unfunctional- 370 ized olefins. ${ }^{51}$ A $91 \%$ ee was observed for $(E)$ - $\alpha$-methylstilbene 371 at 50 bar of $\mathrm{H}_{2}$. Moderate enantioselectivities were found for 372 dihydronaphthalene substrates and 2,3-dimethylindene, while 373 an excellent result was achieved for $\alpha$-ethylstyrene (>99\% ee). 374

Sigman recently reported a novel strategy for the enantio- 375 selective hydrogenation of 1,1-diaryl-substituted olefins, which 376 relies on a remote coordinating effect deriving from a meta 377 substituent on one of the aromatic rings. ${ }^{52}$ In particular, 378 methoxy functionalities were studied as meta directing groups, 379 providing an expansion of the substrate scope compared to the 380 $\mathrm{Ru}$ and $\mathrm{Rh}$ catalytic systems, which required oxygen directing 381 groups in the ortho position. The use of the new proline- 382 derived phosphoramidite (PhosPrOx) ligands 19 (Figure 13) $383 \mathrm{fl} 13$ afforded remarkable ee's (up to 93\%) in the hydrogenation of 384 1,1-diaryl-substituted olefins without an ortho substituent. 385 However, the requirement for a 3,5-dimethoxy substitution 386 on one of the aryls in the substrate in order to reach high 387 enantioselectivity is still limiting the scope of this new 388 
<smiles>C=C(c1ccc(Cl)cc1)c1cc(OC)cc(OC)c1</smiles>

cat. $19,92 \%$ ee<smiles>C=C(c1ccccc1)c1ccccc1C(=O)O</smiles>

cat. $20,99 \%$ ee<smiles>C=C(CCC(=O)O)C(=[In])C(=O)O</smiles>

cat. $20,98 \%$ ee<smiles>C=C(CCC(=O)O)CCC(=O)O</smiles>

cat. $20,96 \%$ ee

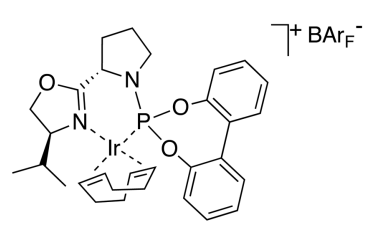

19<smiles>C=C(c1ccc(C(F)(F)F)cc1)c1cc(OC)cc(OC)c1</smiles>

cat. $19,93 \%$ ee<smiles>C=C(c1ccccc1)c1cc(OC)cc(OC)c1</smiles>

cat. $19,85 \%$ ee<smiles>C=C(c1ccc(C)cc1)c1ccccc1C(=O)O</smiles>

\author{
cat. $20,98 \%$ ee
}<smiles>C=CCCCC(=C)CCC(=O)O</smiles>

cat. $20,96 \%$ ee

$$
\text { and 1,1-dialkyl-alkenes. }
$$

Figure 13. Remotely directed asymmetric hydrogenation of 1,1-diaryl-

389 methodology. Zhou applied the same concept via remote 390 carboxyl group coordination in the hydrogenation of 1,1-diaryl391 and 1,1-dialkylethenes. ${ }^{53}$ For the former, the directing $\mathrm{COOH}$ 392 group was placed in the ortho position of one of the aryl 393 substituents and could be readily removed by one-pot 394 decarboxylation, accessing chiral unfunctionalized 1,1-diaryl395 ethanes in high yields and excellent enantioselectivity. These 396 structures are the core of many biologically active compounds. 397 The catalysts contained spiro phosphine-oxazoline ligands 20 398 (Figure 13) and successfully operated at $0.25 \mathrm{~mol} \%$ loading and $3996 \mathrm{~atm}$ of $\mathrm{H}_{2}$ on a broad scope of diarylethene acids ( 96 to $>99 \%$ $400 \mathrm{ee})$. Also for dialkyl substrates, high enantioselectivities were 401 achieved (89-99\% ee), resulting in useful chiral $\gamma$-methyl fatty 402 acids. Asymmetric iridium-catalyzed hydrogenations have 403 generally relied on steric differentiation in order to reach high 404 stereoselectivity, while the coordination strategy had been a 405 prerogative of $\mathrm{Rh}$ - and $\mathrm{Ru}$-mediated processes. Insight into this 406 interesting new strategy in asymmetric hydrogenation and its 407 potential has been highlighted by Reek. ${ }^{54}$

408 The synthesis of chiral benzimidazole-based ligands 21 409 (Figure 14) was reported in 2014 by Müller, and their first

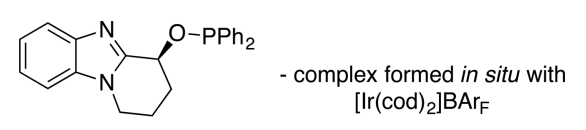

21

Figure 14. Benzimidazole-derived N,P-ligand.

410 application in the asymmetric hydrogenation of (E)- $\alpha$-methyl411 stilbene provided encouraging results (up to $90 \%$ ee). ${ }^{55}$ 412 Optimization of the ligands structure is still to be accomplished, 413 but it could lead to a new competitive class of catalysts in the 414 future.

415 An alternative strategy involving one-pot Cu-catalyzed 416 cycloadditions for the facile preparation of tunable triazole-
Scheme 1. Retrosynthesis of Clickphine N,P-Ligands

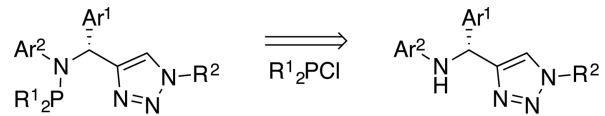

$$
\begin{aligned}
& 22 \\
& \mathrm{~N}_{3}-\mathrm{R}^{2} \Downarrow \text { Cu cat. } \\
& \mathrm{Ar}^{1} \stackrel{\mathrm{OAc}}{\perp}+\mathrm{Ar}^{2}-\mathrm{NH}_{2}
\end{aligned}
$$

developed in 2015 by Reek and van Maarseveen. ${ }^{56}$ Chirality 418 is induced to the ligand libraries from a single copper catalyst, 419 and the process allows the variation of up to four substituents 420 on the triazole-phosphine structure in two reaction steps. These 421 iridium complexes were evaluated in the hydrogenation of 422 largely unfunctionalized olefins; while good ee's were obtained 423 for both examples of (E)-trisubstituted (90\%) and terminal 424 aryl-alkyl-disubstituted subtrates (75\%), they could not equal 425 the excellent results obtained with other classes of Ir-N,P- 426 catalysts. On the other hand, a promising enantioselectivity of 427 $87 \%$ was achieved in the case of a more demanding 428 tetrasubstituted substrate, with very few higher values reported 429 so far.

Iridium N-Heterocyclic Carbene (NHC) Catalysts. In a 431 recent study comparing different NHC,N-ligands, ${ }^{57}$ Burgess 432 concluded that imidazolinylidene $\mathbf{2 3}$, imidazolylidine $\mathbf{3}$, and 433 benzimidazolylidene $\mathbf{2 4}$ structures (Figure 15) show negligible $434 \mathrm{f15}$
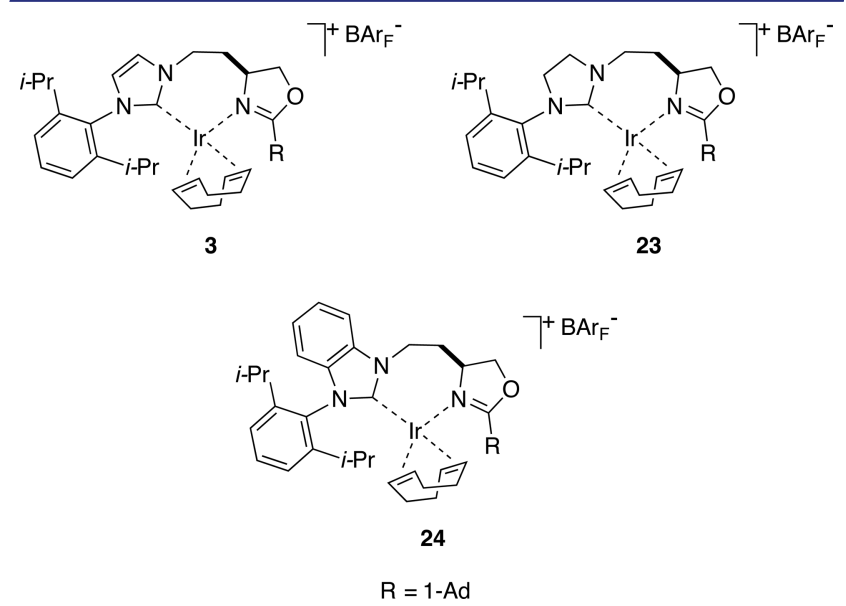

Figure 15. Comparison of NHC,N-catalysts.

differences in catalytic performance in the Ir-catalyzed 435 asymmetric hydrogenation of largely unfunctionalized alkenes. 436 The test substrates were reduced with enantioselectivities 437 comparable to those previously reported for this class of 438 ligands, obtaining excellent results (up to 99\% ee) in the case of 439 (E)-trisubstituted olefins.

440

In 2013, Pfaltz developed a series of NHC-pyridine ligands 441 (25, Figure 16) containing five-, six-, and seven-membered $442 \mathrm{fl} 6$ carbocycles. $^{58}$ These structures combine the features of some of 443 the most successful ligands available to date, and their iridium 444 catalysts proved to be very efficient in the hydrogenation of 445 different unfunctionalized olefins.

446

High levels of enantioselectivity (>90\%) were observed, even 447 for $(Z)$-trisubstituted (94\% ee) and endocyclic substrates (96\% 448 ee). Although they did not outperform Burgess's system 3 in 449 


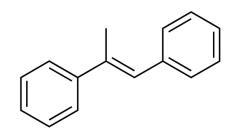<smiles>C/C=C(/C)c1ccc(OC)cc1</smiles>

cat. 25b, 25c, $94 \%$ ee cat. $25 b, 97 \%$ ee
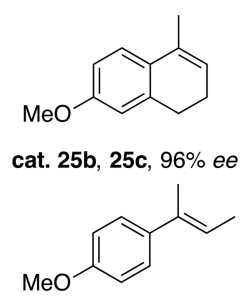

cat. 25a, 25b, 97\% ee cat. $25 b, 25 c, 96 \%$ ee

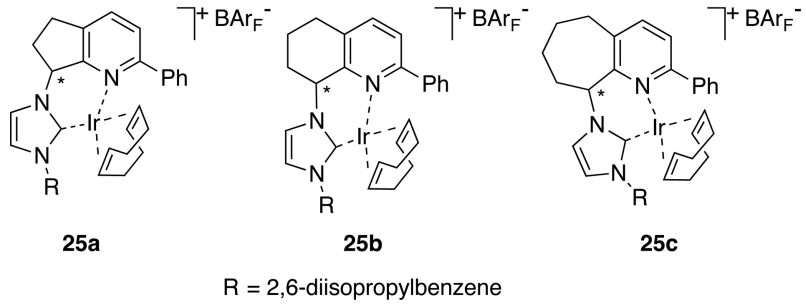

Figure 16. Application of NHC-pyridine catalysts (selected results).

450 the case of terminal disubstituted olefins, these catalysts clearly 451 improve the application range of NHC-iridium ligands to some 452 difficult classes of alkenes. It is worth mentioning that an 453 important advantage of NHC-catalysts compared to their 454 phosphine analogues concerns their better tolerance of acid455 sensitive substrates.

456 Iridium P,S-Catalysts. Sulfur offers the opportunity to 457 create stereogenic centers on the sulfur atom upon 458 coordination with a metal, bringing chirality closer to the 459 metal, and also leading to increased stability of the ligands 460 compared to some commonly employed N-donors. Recent 461 investigations by the group of Pàmies and Diéguez involved the 462 synthesis of various furanoside thioether-phosphite, -phosphin463 ite, and -phosphine ligands 26 (Figure 17), derived from easily 464 accessible $\mathrm{D}-(+)$-xylose. ${ }^{59}$ Structures containing bulky biaryl 465 phosphite moieties afforded highly efficient and enantio466 selective iridium catalysts, which have been evaluated in the 467 hydrogenation of a wide series of minimally functionalized 468 olefins. Excellent ee's (up to 99\%) were obtained for different 469 trisubstituted alkenes, including interesting triaryl-substituted 470 substrates. High enantioselectivities could also be obtained for 471 acyclic ( $Z$ )-olefins (94\% ee), while cyclic substrates were found 472 to result in good but somewhat lower selectivities $(75-86 \%$ 473 ee). High ee could be achieved for vinylboronates (91\%). 474 Challenging 1,1-disubstituted terminal olefins gave low to 475 moderate results when minimally functionalized, depending on 476 the nature of the substrate alkyl substituents. A simpler class of 477 phosphite-phosphinite-thioether ligands (27, Figure 17) 478 derived from cyclohexene oxide was also prepared and 479 evaluated in the asymmetric hydrogenation of various 480 minimally functionalized olefins. ${ }^{60}$ Excellent ee's were reported 481 for several interesting substrates, including trisubstituted 482 alkenylboronic esters ( $85-88 \%$ ee) and tert-butyl-substituted 483 terminal olefins (up to $99 \%$ ee). Furthermore, the catalytic 484 system proved to be highly efficient on terminal aryl-substituted 485 boronic esters (up to $98 \%$ ee), extending the scope of 486 successful asymmetric hydrogenations to this class of olefins. 487 Ferrocene-based P,S-ligands 28 (Figure 17) have been also 488 studied and evaluated in analogous hydrogenation experi489 ments. $^{61}$ However, the best enantioselectivities for non490 functionalized olefins were obtained with the classes of iridium 491 P,S-catalysts based on structures 26 and 27.

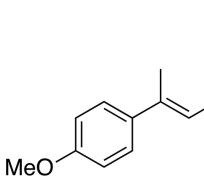

cat. $26,99 \%$ ee

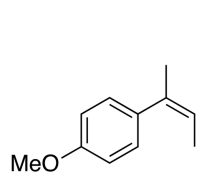

cat. $26,94 \%$ ee

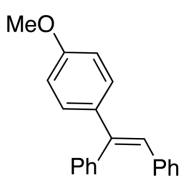

cat. $26,99 \%$ ee

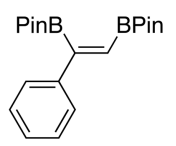

cat. 26, $91 \%$ ee cat. $28,76 \%$ ee<smiles>C=C(c1ccccc1)C(C)(C)C</smiles>

cat. 26, $98 \%$ ee cat. $27,97 \%$ ee<smiles>C=C(c1ccc(OC)cc1)C(C)(C)C</smiles>

cat. $27,98 \%$ ee cat. $28,90 \%$ ee

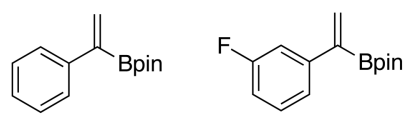

cat. $27,97 \%$ ee $\quad$ cat. $27,98 \%$ ee

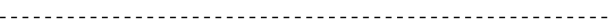

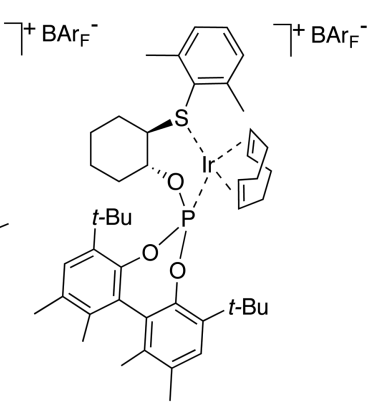

27
26

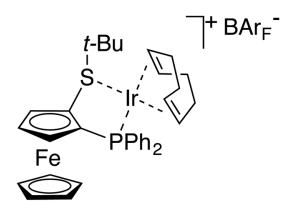

28

Figure 17. Examples of application of P,S-catalysts.

Iridium O,P-Catalysts. In 2011, Pfaltz and co-workers 492 reported the synthesis and evaluation of L-proline-based O,P- 493 ligands 29 (Figure 18) in Ir-catalyzed hydrogenations. ${ }^{62}$ These $494 \mathrm{f18}$

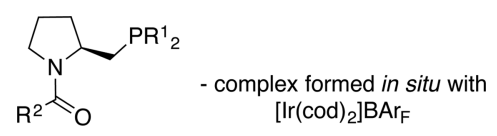

29

Figure 18. Proline-derived $\mathrm{P}, \mathrm{O}$-ligands.

chiral amido- and ureaphosphines can coordinate transition 495 metals through the carbonyl oxygen atom and can be prepared 496 from inexpensive precursors. It was shown that full conversion 497 and excellent enantioselectivities (up to $99 \%$ ee) could be 498 obtained, for example, in the hydrogenation of (E)- $\alpha-499$ methylstilbene, with a performance comparable to that of the 500 best N,P-systems. These O,P-complexes proved, however, to be 501 less stable than proline-based N,P-catalysts and were therefore 502 generated in situ prior to the hydrogenation reaction. These 503 catalysts did not outperform other highly enantioselective N,P- 504 iridium complexes in the case of minimally functionalized 505 trisubstituted olefins, but they have been successfully applied to 506 
507 the hydrogenation of some functionalized olefins, such as $\alpha, \beta$ 508 unsaturated esters and ketones. ${ }^{63}$

509 Rhodium. A dinuclear Rh(III) complex (30, Figure 19) 510 derived from chiral diphosphine ligands was reported for the

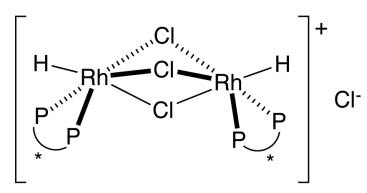

30

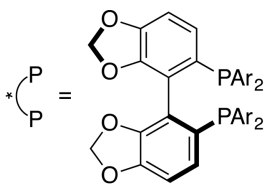

(S)-DTBM-SEGPHOS

$\left(\mathrm{Ar}=3,5-t-\mathrm{Bu}_{2}-4-\mathrm{MeOC}_{6} \mathrm{H}_{2}\right)$
Figure 19. Dinuclear $\mathrm{Rh}(\mathrm{III})$ hydrogenation catalyst.

511 hydrogenation of olefins without directing groups, in contrast 512 to conventional results for $\mathrm{Rh}(\mathrm{I})$ species. ${ }^{64}$ The approach relies 513 on the dissociation into the corresponding mononuclear 514 monohydride $\mathrm{Rh}$ (III) as active species. The precatalyst is a 515 chloride-bridged dinuclear rhodium complex, and a number of 516 structures were generated from a series of chiral diphosphine 517 ligands. Employing bulkier diphosphine ligands resulted in 518 higher activity and selectivity in the hydrogenation of $(E)-\alpha$ 519 methylstilbene (up to $95 \%$ ee) using 30 bar of $\mathrm{H}_{2}$ at $80{ }^{\circ} \mathrm{C}$ in 520 toluene, with 1 mol\% catalyst loading and 2 mol\% of $n-\mathrm{Bu}_{4} \mathrm{NCl}$ 521 as additive. Excellent results (87-98\% ee) were also obtained 522 for a range of methylstilbene derivatives with various aryl 523 substituents. High enantioselectivity could also be achieved in 524 the hydrogenation of alkenyl boranes ( 85 and $93 \%$ ee).

525 Palladium. An interesting report in palladium catalysis 526 involves a chiral [2,2] paracyclophane-based 1,2,3-triazol-5527 ylidene Pd complex (31, Figure 20) containing a labile

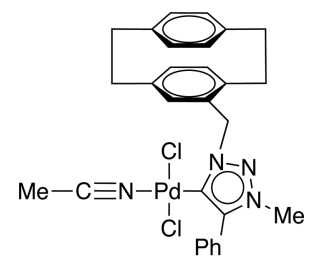

31

Figure 20. Chiral $[2,2]$ paracyclophane-based Pd catalyst.

528 acetonitrile ligand. ${ }^{65}$ It was employed to hydrogenate prochiral 529 olefins under mild conditions in methanol $\left(1\right.$ atm $\mathrm{H}_{2}, 30-35$ $\left.530{ }^{\circ} \mathrm{C}\right)$. When tested on $(E)-\alpha$-methylstilbene and a naphthalene531 substituted terminal alkene, it produced nearly quantitative 532 yields and promising levels of enantioselectivity ( $84-87 \%$ ee). 533 Ligand improvement and screening could result in a substrate 534 scope expansion for this type of catalytic system.

535 Cobalt. An early report by Pfaltz had presented an efficient 536 cobalt catalyst for the enantioselective reduction of $\alpha, \beta$ 537 unsaturated esters. ${ }^{66}$ More recently, Chirik's work made an 538 important contribution to the asymmetric hydrogenation of 539 largely unfunctionalized olefins using cobalt catalysis. This 540 paves the road for the use of more earth-abundant metals; an 541 obviously attractive option in terms of cost and environmental 542 advantages. Cobalt bis(imino)pyridine complexes 32 (Figure 54321 ) have also been successfully employed in the asymmetric 544 hydrogenation of challenging terminal aryl,alkyl-substituted 545 olefins and furnished the corresponding saturated products in 546 high enantioselectivity (>90\% ee). ${ }^{67}$ A particularly remarkable 547 result is the excellent $96 \%$ ee observed in the formation of 1 -

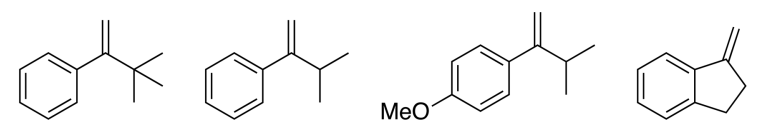

cat. 32a, $>98 \%$ ee cat. $32 a, 90 \%$ ee $\quad$ cat. 32 a, $94 \%$ ee $\quad$ cat. 32 b, $96 \%$ ee<smiles>C/C(=C\c1ccccc1)c1ccccc1</smiles>

cat. $33,94 \%$ ee<smiles>C=C(c1cccc(OC)c1)c1ccccc1Cl</smiles>

cat. $34,95 \%$ ee<smiles>C=C(c1cccc(C(F)(F)F)c1)c1ccccc1Cl</smiles>

cat. $34,>99 \%$ ee<smiles>C=C(c1cccc(OC)c1)c1ccccc1C</smiles><smiles>C1=C(c2ccccc2)c2ccccc2C1</smiles><smiles>Fc1ccc(C2=CCc3ccccc32)cc1</smiles><smiles>C1=C(c2ccccc2)c2ccccc2CC1</smiles>

cat. $34,91 \%$ ee cat. $32 a, 97 \%$ ee cat. $32 a, 98 \%$ ee

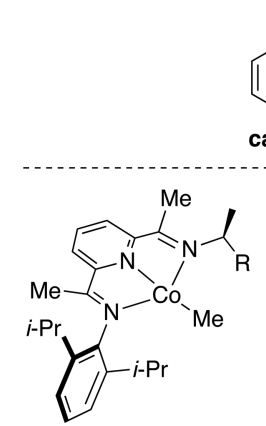

32a $\mathrm{R}=\mathrm{Cy}$ 32b $R=t-B u$ cat. $32 \mathrm{a}, 94 \%$ ee<smiles>CC1=CCCc2ccccc21</smiles>

$$
\text { , } 93 \% \text { ee }
$$

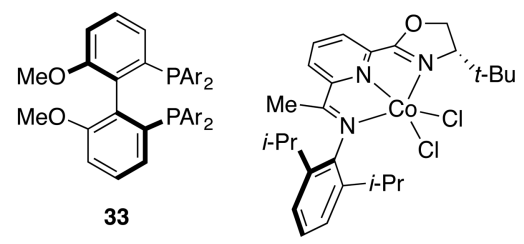

34

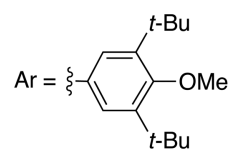

in combination with

(py) ${ }_{2} \mathrm{Co}\left(\mathrm{CH}_{2} \mathrm{SiMe}_{3}\right)_{2}$

Figure 21. Cobalt-catalyzed asymmetric hydrogenation of unfunctionalized olefins (selected results).

methylindane. Hopmann recently presented a quantum 548 mechanical study of the chiral CoBIP catalysts, providing 549 information about their properties, activation paths and 550 asymmetric hydrogenation mechanism. ${ }^{68}$ Competitive alkene 551 isomerization was shown to play a role in the overall process, 552 affecting also the observed enantioselectivities.

553

Successively, high-throughput screening of numerous chiral 554 bidentate phosphine ligands in combination with different 555 cobalt precursors allowed the identification of a suitable 556 catalytic system for the asymmetric hydrogenation of $(E)-\alpha-557$ methylstilbene. ${ }^{69}$ Ultimately, a Biphep derivative (ligand 33, 558 Figure 21) was found to be highly stereoselective, resulting in 559 $83 \%$ conversion and $94 \%$ ee, after $20 \mathrm{~h}$ using $34 \mathrm{~atm}$ of $\mathrm{H}_{2}$. The 560 catalyst loadings are higher (10 or $5 \mathrm{~mol} \%$ ) than those 561 commonly used for iridium catalysts ( $1 \mathrm{~mol} \%$ or less), but these 562 results certainly prove cobalt to be a valuable asset for efficient 563 and versatile hydrogenation of largely unfunctionalized olefins. 564

Both $\mathrm{Lu}$ and Chirik reported the Co-catalyzed enantio- 565 selective hydrogenation of several 1,1-diarylethenes in 2016. In 566 Lu's case, ${ }^{70}$ a stable cobalt complex containing an oxazoline 567 iminopyridine chiral ligand (34, Figure 21) was used as 568 precatalyst. In the presence of $\mathrm{NaBHEt}_{3}$ in toluene and using 1569 atm of $\mathrm{H}_{2}$ at room temperature, it was possible to reach full 570 conversion and $90 \%$ ee for substrates with an ortho- $\mathrm{Cl}$ group, 571 which provided a unique effect to achieve high enantio- 572 selectivities. When the alkene scope was evaluated, enantio- 573 
574 selectivities up to $95 \%$ ee were observed for $\alpha$-alkylstyrenes. 575 The $\mathrm{Cl}$ group could then be removed or used for further 576 functionalizations with excellent yields, describing a convenient 577 way to obtain various chiral 1,1-diarylethanes.

578 In Chirik's report, cobalt bis(imino)pyridine complexes 32 579 proved very successful in the asymmetric hydrogenation of 580 cyclic unfunctionalized olefins, such as aryl-substituted indenes 581 and dialins (up to $99 \%$ ee). ${ }^{71}$ In a comparative study, both 582 isomeric exo- and endocyclic alkenes were hydrogenated in 583 good to high enantioselectivity (up to $95 \%$ ee), with a tendency 584 to show opposite stereochemical outcomes. Moderate ee's (up 585 to $77 \%$ ) were obtained for 1,1-diarylethenes when ortho 586 substitution was present. A remarkable application of the 587 catalytic system is the multigram-scale reduction of 4-methyl588 1,2-dihydronaphthalene (93\% ee), carried out in neat alkene 589 using $0.1 \mathrm{~mol} \%$ of chiral cobalt complex. Co-hydride species 590 were rapidly generated in the presence of $\mathrm{H}_{2}$ and were 591 identified by means of NMR and X-ray diffraction, providing 592 some information about the chiral environment around the 593 cobalt.

594 Iron. Aryl-substituted bis(imino)pyridine iron dinitrogen 595 complexes $\mathbf{3 5}$ (Figure 22) were described as efficient base metal

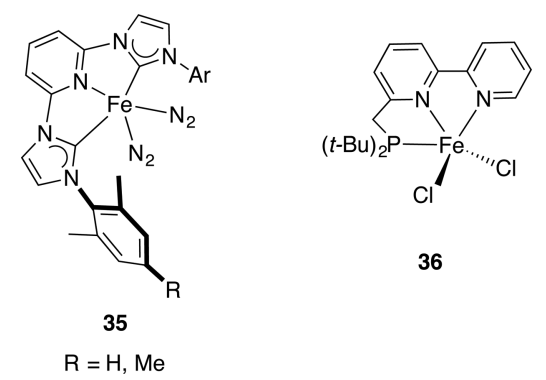

Figure 22. Iron catalysts for the hydrogenation of simple olefins.

596 catalysts, exhibiting high turnover frequencies for the hydro597 genation of unfunctionalized trisubstituted and challenging 598 tetrasubstituted olefins, employing iron loadings as low as 0.3 $599 \mathrm{~mol} \%$ at room temperature. ${ }^{72}$ Recent optimization of the ligand 600 design using more electron-rich structures improved the 601 performance. ${ }^{73}$ This work could furnish valuable insight for 602 the development of an asymmetric version of iron catalytic 603 systems.

604 Another class of iron catalysts was reported where the active 605 species are generated in situ by reduction of stable $\mathrm{Fe}$ (II) 606 complexes with $\mathrm{LiAlH}_{4}{ }^{74}$ The use of bidentate N,N-ligands 607 resulted in excellent activity in the hydrogenation of styrene, 608 which was fully saturated in less than $1 \mathrm{~h}$ using 30 atm of $\mathrm{H}_{2}$ 609 with $0.1 \mathrm{~mol} \%$ catalyst loading. A particularly efficient catalyst 610 was then obtained using a pincer bipyridine ligand (36, Figure 61122 ), which provided full conversion after $3 \mathrm{~h}$ using $10 \mathrm{~atm}$ of $612 \mathrm{H}_{2}$, at $0.01 \mathrm{~mol} \%$ catalyst loading. Styrenes and aliphatic 613 terminal olefins were also hydrogenated with high reaction 614 rates; however, it was necessary to increase the temperature to $61550{ }^{\circ} \mathrm{C}$ in the case of disubstituted olefins. This contribution also 616 makes it possible to envision further developments toward Fe617 based asymmetric hydrogenation catalysts.

\section{CONCLUSIONS AND OPEN CHALLENGES}

619 The development of chiral Crabtree-type catalysts has notably 620 expanded the field of homogeneous asymmetric hydrogenation 621 of nonfunctionalized olefins, providing complementarity to Rh and $\mathrm{Ru}$ systems. Examining the scope of the catalysts that are 622 currently available for the asymmetric hydrogenation of largely 623 unfunctionalized olefins, it seems clear that careful ligand 624 optimization and control of the reaction conditions allow 625 reaching high enantioselectivities for many different substrate 626 classes. One drawback of this approach is the lack of generality 627 of the catalysts; it is still difficult to generate a single catalyst 628 that would tolerate a large number of olefins bearing 629 substituents of diverse nature. However, recent investigations, 630 especially in iridium catalysis, continue to produce new 631 powerful systems, advancing toward the goal of increased 632 functional group tolerance. The main limitation that still 633 concerns the majority of asymmetric hydrogenations is the 634 necessity to operate on pure geometrical isomers; $(E)$ - and $(Z)-635$ trisubstituted olefins are generally found to produce opposite 636 enantiomers of the alkane products, canceling the chance of 637 achieving high stereoselectivity when both are present. The 638 reason for this undesired behavior lies in the mode the catalysts 639 are discriminating between the prochiral faces of the olefin, 640 with the favored coordination being dictated by the less 641 substituted carbon atom rather than the prochiral center. 642 Therefore, a catalytic system that would be able to select 643 directly on the prochiral carbon, regardless of alkene geometry, 644 is much sought after, as it would enable the asymmetric 645 hydrogenation of $E / Z$ mixtures to yield enantiomerically pure 646 products. This issue is even more relevant in the case of 647 unfunctionalized olefins, since the presence of functional 648 groups on the substrates facilitates both the stereoselective 649 synthesis of either (E)- or (Z)-isomers and also their 650 separation.

651

Another open challenge concerns the development of 652 efficient systems for hindered tetrasubstituted olefins. This 653 class of substrates has always proved very demanding, and 654 reports of highly enantioselective hydrogenations are still 655 scarce. One interesting feature of tetrasubstituted olefins is 656 certainly the opportunity to generate two contiguous stereo- 657 centers in a single reaction; thus, efforts in the development of 658 improved catalysts for these sterically challenging compounds 659 are easy to foresee.

Other demanding substrates are also represented by olefins 661 that contain non-coordinating groups such as silanes or halides. 662 In the latter case, the hydrogenation is further complicated by 663 competing dehalogenation processes, an issue still to be 664 overcome by development of new catalytic systems. 665

In addition to handling these difficult classes of alkenes, it 666 would also be highly desirable to directly saturate aromatic 667 rings, which would be one of the most interesting opportunities 668 for the asymmetric hydrogenation of minimally functionalized 669 substrates. Several efficient catalysts have been developed for 670 the asymmetric hydrogenation of various classes of hetero- 671 arenes, and these advances have been reviewed in detail by 672 Zhou and Glorius. ${ }^{75}$ Some examples of catalytic hydrogenation 673 of benzene rings have been reported, ${ }^{76}$ but still the substrate 674 scope remains very narrow, and this research area is also likely 675 to expand in the future.

676

The formation of multiple stereocenters from the asymmetric 677 hydrogenation of polyene substrates is of undoubtable interest, 678 and the usefulness of this strategy has been elegantly 679 demonstrated in natural products preparation. ${ }^{16 \mathrm{~b}, 77}$ On the 680 other hand, polyenes can also offer many other interesting post- 681 hydrogenation synthetic possibilities if the catalytic system can 682 be tuned to react with one olefin while leaving others 683 untouched and available for further functionalization. It 684 
685 would represent a powerful synthetic tool to induce chirality, 686 especially in complex structures containing many double bonds. 687 Examples of regioselective iridium catalysts have been recently 688 reported $^{45}$ and can surely offer a hint for future studies on this 689 subject.

690 Finally, a fundamental area of investigation lies in the search 691 for catalysts based on more cost-effective and environmentally 692 friendly Earth-abundant metals, exemplified by recent works in 693 cobalt and iron catalysis. In the former case, some excellent 694 results for the asymmetric hydrogenation of unfuctionalized 695 olefins have already been reported, and the optimization of 696 catalytic activity and stability are plausible lines of forthcoming 697 development. In the case of Fe-catalyzed hydrogenation of 698 olefins, the challenge is instead to design an efficient 699 asymmetric variant of the newly developed achiral systems.

700 Taking the above-mentioned considerations into account, 701 one can conclude that many fascinating aspects and 702 opportunities of the asymmetric hydrogenation of minimally 703 functionalized olefins remain to be explored and that the design 704 of innovative catalysts capable of overcoming the remaining 705 issues would provide fundamental contributions to the field.

\section{AUTHOR INFORMATION}

707 Corresponding Author

708 *pher.andersson@su.se

709 ORCID

710 Pher G. Andersson: 0000-0002-1383-8246

711 Notes

712 The authors declare no competing financial interest.

\section{ACKNOWLEDGMENTS}

714 The Knut and Alice Wallenberg foundation and Stiftelsen Olle 715 Engkvist Byggmas̈tare are acknowledged for financial support.

\section{$716 \square$ REFERENCES}

717 (1) (a) Jacobsen, E. N.; Pfaltz, A.; Yamamoto, H. Comprehensive 718 asymmetric catalysis: I-III; Springer: Berlin, 1999. (b) Ohkuma, T.; 719 Kitamura, M.; Noyori, R. In Catalytic Asymmetric Synthesis, 2nd ed.; 720 Ojima, I., Ed.; Wiley-VCH: Weinheim, 2000.

721 (2) (a) Evans, D.; Osborn, J. A.; Jardine, F. H.; Wilkinson, G. Nature 722 1965, 208, 1203. (b) Horner, L.; Siegel, H.; Büthe, H. Angew. Chem., 723 Int. Ed. Engl. 1968, 7, 942. (c) Knowles, W. S.; Sabacky, M. J. Chem. 724 Commun. 1968, 1445. (d) Dang, T. P.; Kagan, H. B. J. Chem. Soc. D 725 1971, 481. (e) Knowles, W. S.; Sabacky, M. J.; Vineyard, B. D. J. Chem. 726 Soc., Chem. Commun. 1972, 10. (f) Tanaka, M.; Ogata, I. J. Chem. Soc., 727 Chem. Commun. 1975, 735a. (g) Kawabata, Y.; Tanaka, M.; Ogata, I. 728 Chem. Lett. 1976, 5, 1213. (h) Hayashi, T.; Tanaka, M.; Ogata, I. 729 Tetrahedron Lett. 1977, 18, 295. (i) Vineyard, B. D.; Knowles, W. S.; 730 Sabacky, M. J.; Bachman, G. L.; Weinkauff, D. J. J. Am. Chem. Soc. 731 1977, 99, 5946. (j) Knowles, W. S. Acc. Chem. Res. 1983, 16, 106. 732 (k) Bakos, J.; Tóth, I.; Heil, B.; Markó, L. J. Organomet. Chem. 1985, 733 279, 23. (1) Inagaki, K.; Ohta, T.; Nozaki, K.; Takaya, H. J. Organomet. 734 Chem. 1997, 531, 159.

735 (3) Noyori, R.; Ohkuma, T.; Kitamura, M.; Takaya, H.; Sayo, N.; 736 Kumobayashi, H.; Akutagawa, S. J. Am. Chem. Soc. 1987, 109, 5856.

737 (4) (a) Ohta, T.; Ikegami, H.; Miyake, T.; Takaya, H. J. Organomet. 738 Chem. 1995, 502, 169. (b) Schmid, R.; Broger, E. A.; Cereghetti, M.; 739 Crameri, Y.; Foricher, J.; Lalonde, M.; Müller, R. K.; Scalone, M.; 740 Schoettel, G.; Zutter, U. Pure Appl. Chem. 1996, 68, 131. (c) Forman, 741 G. S.; Ohkuma, T.; Hems, W. P.; Noyori, R. Tetrahedron Lett. 2000, $74241,9471$.

743 (5) Cui, X.; Burgess, K. Chem. Rev. 2005, 105, 3272.

744 (6) (a) Cesarotti, E.; Ugo, R.; Kagan, H. B. Angew. Chem., Int. Ed. 745 Engl. 1979, 18, 779. (b) Paquette, L. A.; McKinney, J. A.; McLaughlin, 746 M. L.; Rheingold, A. L. Tetrahedron Lett. 1986, 27, 5599. (c) Halter- man, R. L.; Vollhardt, K. P. C.; Welker, M. E.; Blaeser, D.; Boese, R. J. 747 Am. Chem. Soc. 1987, 109, 8105. (d) Halterman, R. L.; Vollhardt, K. P. 748 C. Organometallics 1988, 7, 883. (e) Pino, P.; Galimberti, M. J. 749 Organomet. Chem. 1989, 370, 1. (f) Waymouth, R.; Pino, P. J. Am. 750 Chem. Soc. 1990, 112, 4911. (g) Grossman, R. B.; Doyle, R. A.; 751 Buchwald, S. L. Organometallics 1991, 10, 1501. (h) Broene, R. D.; 752 Buchwald, S. L. J. Am. Chem. Soc. 1993, 115, 12569. (i) Gibis, K.-L.; 753 Helmchen, G.; Huttner, G.; Zsolnai, L. J. Organomet. Chem. 1993, 445, 754 181. (j) Paquette, L. A.; Sivik, M. R.; Bzowej, E. I.; Stanton, K. J. 755 Organometallics 1995, 14, 4865. (k) Richards, C. J.; Locke, A. J. 756 Tetrahedron: Asymmetry 1998, 9, 2377. (1) Schwink, L.; Knochel, P. 757 Chem. - Eur. J. 1998, 4, 950. (m) Troutman, M. V.; Appella, D. H.; 758 Buchwald, S. L. J. Am. Chem. Soc. 1999, 121, 4916.

(7) (a) Conticello, V. P.; Brard, L.; Giardello, M. A.; Tsuji, Y.; Sabat, 760 M.; Stern, C. L.; Marks, T. J. J. Am. Chem. Soc. 1992, 114, 2761. 761 (b) Giardello, M. A.; Conticello, V. P.; Brard, L.; Gagne, M. R.; Marks, 762 T. J. J. Am. Chem. Soc. 1994, 116, 10241. (c) Haar, C. M.; Stern, C. L.; 763 Marks, T. J. Organometallics 1996, 15, 1765. (d) Roesky, P. W.; 764 Denninger, U.; Stern, C. L.; Marks, T. J. Organometallics 1997, 16, 765 4486.

(8) Crabtree, R. Acc. Chem. Res. 1979, 12, 331.

766

(9) Sprinz, J.; Helmchen, G. Tetrahedron Lett. 1993, 34, 1769.

(10) Dawson, G. J.; Frost, C. G.; Williams, J. M. J.; Coote, S. J. 769 Tetrahedron Lett. 1993, 34, 3149.

(11) (a) von Matt, P.; Pfaltz, A. Angew. Chem., Int. Ed. Engl. 1993, 32, 771 566. (b) von Matt, P.; Loiseleur, O.; Koch, G.; Pfaltz, A.; Lefeber, C.; 772 Feucht, T.; Helmchen, G. Tetrahedron: Asymmetry 1994, 5, 573. 773 (c) Koch, G.; Pfaltz, A. Tetrahedron: Asymmetry 1996, 7, 2213. (12) Schnider, P.; Koch, G.; Prétôt, R.; Wang, G.; Bohnen, F. M.; 775 Krüger, C.; Pfaltz, A. Chem. - Eur. J. 1997, 3, 887.

(13) Lightfoot, A.; Schnider, P.; Pfaltz, A. Angew. Chem., Int. Ed. 777 1998, 37, 2897.

(14) Smidt, S. P.; Zimmermann, N.; Studer, M.; Pfaltz, A. Chem. - 779 Eur. J. 2004, 10, 4685.

(15) (a) Hilgraf, R.; Pfaltz, A. Synlett 1999, 1999, 1814. (b) Black- 781 mond, D. G.; Lightfoot, A.; Pfaltz, A.; Rosner, T.; Schnider, P.; 782 Zimmermann, N. Chirality 2000, 12, 442. (c) Bernardinelli, G. H.; 783 Kündig, E. P.; Meier, P.; Pfaltz, A.; Radkowski, K.; Zimmermann, N.; 784 Neuburger-Zehnder, M. Helv. Chim. Acta 2001, 84, 3233. 785 (d) Blankenstein, J.; Pfaltz, A. Angew. Chem., Int. Ed. 2001, 40, 4445. 786 (e) Menges, F.; Neuburger, M.; Pfaltz, A. Org. Lett. 2002, 4, 4713. 787 (f) Menges, F.; Pfaltz, A. Adv. Synth. Catal. 2002, 344, 40. (g) Smidt, S. 788 P.; Menges, F.; Pfaltz, A. Org. Lett. 2004, 6, 2023. (h) Hilgraf, R.; 789 Pfaltz, A. Adv. Synth. Catal. 2005, 347, 61. (i) Schönleber, M.; Hilgraf, 790 R.; Pfaltz, A. Adv. Synth. Catal. 2008, 350, 2033.

(16) (a) Drury, W. J.; Zimmermann, N.; Keenan, M.; Hayashi, M.; 792 Kaiser, S.; Goddard, R.; Pfaltz, A. Angew. Chem., Int. Ed. 2004, 43, 70. 793 (b) Bell, S.; Wüstenberg, B.; Kaiser, S.; Menges, F.; Netscher, T.; 794 Pfaltz, A. Science 2006, 311, 642. (c) Woodmansee, D. H.; Muller, M.- 795 A.; Neuburger, M.; Pfaltz, A. Chemical Science 2010, 1, 72.

(17) Woodmansee, D. H.; Müller, M.-A.; Tröndlin, L.; Hörmann, E.; 797 Pfaltz, A. Chem. - Eur. J. 2012, 18, 13780.

(18) Kaiser, S.; Smidt, S. P.; Pfaltz, A. Angew. Chem., Int. Ed. 2006, 45, 799 5194.

(19) Ganić, A.; Pfaltz, A. Chem. - Eur. J. 2012, 18, 6724.

(20) Schrems, M. G.; Neumann, E.; Pfaltz, A. Angew. Chem., Int. Ed. 802 2007, 46, 8274.

(21) (a) Powell, M. T.; Hou, D.-R.; Perry, M. C.; Cui, X.; Burgess, K J. Am. Chem. Soc. 2001, 123, 8878. (b) Perry, M. C.; Cui, X.; Powell, 805 M. T.; Hou, D.-R.; Reibenspies, J. H.; Burgess, K. J. Am. Chem. Soc. 806 2003, 125, 113.

(22) Zhu, Y.; Burgess, K. Adv. Synth. Catal. 2008, 350, 979.

(23) Källström, K.; Hedberg, C.; Brandt, P.; Bayer, A.; Andersson, P. 809 G. J. Am. Chem. Soc. 2004, 126, 14308.

(24) Hedberg, C.; Källström, K.; Brandt, P.; Hansen, L. K.; 811 Andersson, P. G. J. Am. Chem. Soc. 2006, 128, 2995.

(25) Kaukoranta, P.; Engman, M.; Hedberg, C.; Bergquist, J.; 813 Andersson, P. G. Adv. Synth. Catal. 2008, 350, 1168. 
815 (26) (a) Li, J.-Q.; Paptchikhine, A.; Govender, T.; Andersson, P. G. 816 Tetrahedron: Asymmetry 2010, 21, 1328. (b) Trifonova, A.; Diesen, J. 817 S.; Andersson, P. G. Chem. - Eur. J. 2006, 12, 2318.

818 (27) Källström, K.; Munslow, I. J.; Hedberg, C.; Andersson, P. G. 819 Adv. Synth. Catal. 2006, 348, 2575.

820 (28) Engman, M.; Diesen, J. S.; Paptchikhine, A.; Andersson, P. G. J. 821 Am. Chem. Soc. 2007, 129, 4536.

822 (29) Paptchikhine, A.; Cheruku, P.; Engman, M.; Andersson, P. G. 823 Chem. Commun. 2009, 5996.

824 (30) Cheruku, P.; Diesen, J.; Andersson, P. G. J. Am. Chem. Soc. 825 2008, 130, 5595.

826 (31) (a) Verendel, J. J.; Pàmies, O.; Diéguez, M.; Andersson, P. G. 827 Chem. Rev. 2014, 114, 2130. (b) Woodmansee, D. H.; Pfaltz, A. Chem. 828 Commun. 2011, 47, 7912. (c) Halterman, R. L. Comprehensive 829 Asymmetric Catalysis: Supplement 2; Springer: Berlin, 2004. (d) Rose830 blade, S. J.; Pfaltz, A. Acc. Chem. Res. 2007, 40, 1402. (e) Pàmies, O.; 831 Andersson, P. G.; Diéguez, M. Chem. - Eur. J. 2010, 16, 14232. 832 (f) Cadu, A.; Andersson, P. G. Dalton Trans. 2013, 42, 14345.

833 (32) Co, T. T.; Kim, T.-J. Chem. Commun. 2006, 3537.

834 (33) (a) Crabtree, R. H.; Felkin, H.; Morris, G. E. J. Organomet. 835 Chem. 1977, 141, 205. (b) Crabtree, R. H.; Felkin, H.; Fillebeen-Khan, 836 T.; Morris, G. E. J. Organomet. Chem. 1979, 168, 183. (c) Crabtree, R. 837 H.; Demou, P. C.; Eden, D.; Mihelcic, J. M.; Parnell, C. A.; Quirk, J. 838 M.; Morris, G. E. J. Am. Chem. Soc. 1982, 104, 6994. (d) Dietiker, R.; 839 Chen, P. Angew. Chem., Int. Ed. 2004, 43, 5513. (e) Fan, Y.; Cui, X.; 840 Burgess, K.; Hall, M. B. J. Am. Chem. Soc. 2004, 126, 16688. (f) Mazet, 841 C.; Smidt, S. P.; Meuwly, M.; Pfaltz, A. J. Am. Chem. Soc. 2004, 126, 84214176.

843 (34) Brandt, P.; Hedberg, C.; Andersson, P. G. Chem. - Eur. J. 2003, $8449,339$.

845 (35) Sun, Y.; Landau, R. N.; Wang, J.; LeBlond, C.; Blackmond, D. 846 G. J. Am. Chem. Soc. 1996, 118, 1348.

847 (36) Church, T. L.; Rasmussen, T.; Andersson, P. G. Organometallics 848 2010, 29, 6769.

849 (37) (a) Hopmann, K. H.; Bayer, A. Organometallics 2011, 30, 2483. 850 (b) Hopmann, K. H.; Frediani, L.; Bayer, A. Organometallics 2014, 33, 851 2790. (c) Sparta, M.; Riplinger, C.; Neese, F. J. Chem. Theory Comput. 852 2014, 10, 1099.

853 (38) Gruber, S.; Pfaltz, A. Angew. Chem., Int. Ed. 2014, 53, 1896.

854 (39) Mazuela, J.; Norrby, P.-O.; Andersson, P. G.; Pàmies, O.; 855 Diéguez, M. J. Am. Chem. Soc. 2011, 133, 13634.

856 (40) Mazuela, J.; Pàmies, O.; Diéguez, M. Eur. J. Inorg. Chem. 2013, $8572013,2139$.

858 (41) Mazuela, J.; Pàmies, O.; Diéguez, M. ChemCatChem 2013, 5, 8592410.

860 (42) Mazuela, J.; Pàmies, O.; Diéguez, M. Adv. Synth. Catal. 2013, $861355,2569$.

862 (43) Biosca, M.; Paptchikhine, A.; Pàmies, O.; Andersson, P. G.; 863 Diéguez, M. Chem. - Eur. J. 2015, 21, 3455.

864 (44) (a) Cadu, A.; Paptchikhine, A.; Andersson, P. G. Synthesis 2011, 865 2011, 3796. (b) Paptchikhine, A.; Itto, K.; Andersson, P. G. Chem. 866 Commun. 2011, 47, 3989.

867 (45) Peters, B. K.; Liu, J.; Margarita, C.; Rabten, W.; Kerdphon, S.; 868 Orebom, A.; Morsch, T.; Andersson, P. G. J. Am. Chem. Soc. 2016, $869138,11930$.

870 (46) Quan, X.; Parihar, V. S.; Bera, M.; Andersson, P. G. Eur. J. Org. 871 Chem. 2014, 2014, 140.

872 (47) Yotapan, N.; Paptchikhine, A.; Bera, M.; Avula, S. K.; Vilaivan, 873 T.; Andersson, P. G. Asian J. Org. Chem. 2013, 2, 674.

874 (48) Busacca, C. A.; Qu, B.; Grět, N.; Fandrick, K. R.; Saha, A. K.; 875 Marsini, M.; Reeves, D.; Haddad, N.; Eriksson, M.; Wu, J.-P.; 876 Grinberg, N.; Lee, H.; Li, Z.; Lu, B.; Chen, D.; Hong, Y.; Ma, S.; 877 Senanayake, C. H. Adv. Synth. Catal. 2013, 355, 1455.

878 (49) Qu, B.; Samankumara, L. P.; Savoie, J.; Fandrick, D. R.; Haddad, 879 N.; Wei, X.; Ma, S.; Lee, H.; Rodriguez, S.; Busacca, C. A.; Yee, N. K.; 880 Song, J. J.; Senanayake, C. H. J. Org. Chem. 2014, 79, 993.

881 (50) Qu, B.; Samankumara, L. P.; Ma, S.; Fandrick, K. R.; Desrosiers, 882 J.-N.; Rodriguez, S.; Li, Z.; Haddad, N.; Han, Z. S.; McKellop, K.;
Pennino, S.; Grinberg, N.; Gonnella, N. C.; Song, J. J.; Senanayake, C. 883 H. Angew. Chem., Int. Ed. 2014, 53, 14428.

(51) Bert, K.; Noel, T.; Kimpe, W.; Goeman, J. L.; Van der Eycken, J. 885 Org. Biomol. Chem. 2012, 10, 8539.

(52) Bess, E. N.; Sigman, M. S. Org. Lett. 2013, 15, 646.

(53) Song, S.; Zhu, S.-F.; Yu, Y.-B.; Zhou, Q.-L. Angew. Chem., Int. 888 Ed. 2013, 52, 1556.

(54) Besset, T.; Gramage-Doria, R.; Reek, J. N. H. Angew. Chem., Int. 890 Ed. 2013, 52, 8795.

(55) Weemers, J. J. M.; Sypaseuth, F. D.; Bäuerlein, P. S.; van der 892 Graaff, W. N. P.; Filot, I. A. W.; Lutz, M.; Müller, C. Eur. J. Org. Chem. 893 2014, 2014, 350.

(56) Wassenaar, J.; Detz, R. J.; de Boer, S. Y.; Lutz, M.; van 895 Maarseveen, J. H.; Hiemstra, H.; Reek, J. N. H. J. Org. Chem. 2015, 80, 896 3634.

(57) Khumsubdee, S.; Fan, Y.; Burgess, K. J. Org. Chem. 2013, 78, 898 9969.

(58) Schumacher, A.; Bernasconi, M.; Pfaltz, A. Angew. Chem., Int. Ed. 900 2013, 52, 7422 .

(59) Coll, M.; Pàmies, O.; Diéguez, M. Adv. Synth. Catal. 2013, 355, 902 143.

(60) Borràs, C.; Biosca, M.; Pàmies, O.; Diéguez, M. Organometallics 904 2015, 34, 5321.

(61) Biosca, M.; Coll, M.; Lagarde, F.; Brémond, E.; Routaboul, L.; 906 Manoury, E.; Pàmies, O.; Poli, R.; Diéguez, M. Tetrahedron 2016, 72, 907 2623.

(62) Rageot, D.; Woodmansee, D. H.; Pugin, B.; Pfaltz, A. Angew. 909 Chem., Int. Ed. 2011, 50, 9598.

(63) Rageot, D.; Pfaltz, A. Helv. Chim. Acta 2012, 95, 2176.

(64) Kita, Y.; Hida, S.; Higashihara, K.; Jena, H. S.; Higashida, K.; 912 Mashima, K. Angew. Chem., Int. Ed. 2016, 55, 8299.

(65) Dasgupta, A.; Ramkumar, V.; Sankararaman, S. RSC Adv. 2015, 914 $5,21558$.

(66) Pfaltz, A. Bull. Soc. Chim. Belg. 1990, 99, 729. 915

(67) Monfette, S., Turner, Z. R. Semproni, S. P. Chirik, P. J. J. Am. 917 Chem. Soc. 2012, 134, 4561.

(68) Hopmann, K. H. Organometallics 2013, 32, 6388.

(69) Friedfeld, M. R.; Shevlin, M.; Hoyt, J. M.; Krska, S. W.; Tudge, 920 M. T.; Chirik, P. J. Science 2013, 342, 1076.

(70) Chen, J.; Chen, C.; Ji, C.; Lu, Z. Org. Lett. 2016, 18, 1594.922

(71) Friedfeld, M. R.; Shevlin, M.; Margulieux, G. W.; Campeau, L.- 923 C.; Chirik, P. J. J. Am. Chem. Soc. 2016, 138, 3314.

(72) Bart, S. C.; Lobkovsky, E.; Chirik, P. J. J. Am. Chem. Soc. 2004, 925 126, 13794.

(73) Yu, R. P.; Darmon, J. M.; Hoyt, J. M.; Margulieux, G. W.; 927 Turner, Z. R.; Chirik, P. J. ACS Catal. 2012, 2, 1760.

(74) Guo, N.; Hu, M.-Y.; Feng, Y.; Zhu, S.-F. Org. Chem. Front. 2015, 929 2, 692 .

(75) (a) Wang, D.-S.; Chen, Q.-A.; Lu, S.-M.; Zhou, Y.-G. Chem. Rev. 931 2012, 112, 2557. (b) Chen, Z.-P.; Zhou, Y.-G. Synthesis 2016, 48, 932 1769. (c) Zhao, D.; Candish, L.; Paul, D.; Glorius, F. ACS Catal. 2016, 933 6, 5978.

(76) Wei, Y.; Rao, B.; Cong, X.; Zeng, X. J. Am. Chem. Soc. 2015, 137, 935 9250.

(77) Zhou, J.; Burgess, K. Angew. Chem., Int. Ed. 2007, 46, 1129.937 